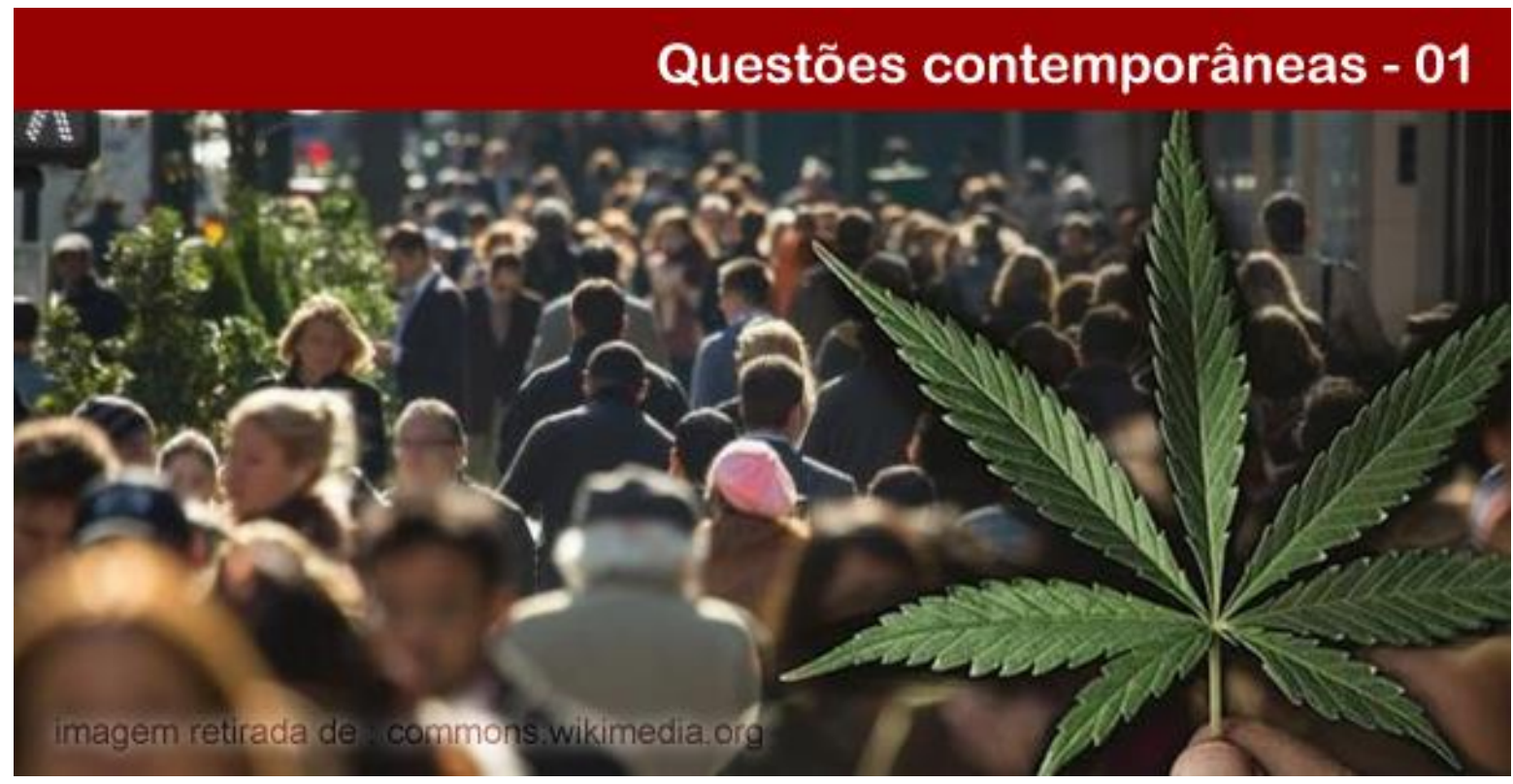

\title{
O CONHECIMENTO NAS MARGENS, OUTSIDERS E A EDUCAÇÃO POPULAR DESAFIADA: UMA ABORDAGEM SOBRE AS DROGAS E O TRABALHO SOCIOEDUCATIVO
}

\author{
Ivonaldo Leite \\ PhD em Ciências da Educação/Sociologia da Educação pela Universidade do Porto, Portugal. Coordenador do \\ Grupo de Estudos e Pesquisas em Educação, Sociedade e Culturas da Universidade Federal da Paraíba \\ (GEPEDUSC/UFPB-CNPq).E-mail: ivonaldo.leite@gmail.com.
}

Resumo: Este trabalho decorre de uma pesquisa de pós-doutorado mais ampla. Ele tem como objetivo desenvolver uma análise no sentido de apresentar uma perspectiva de abordagem sobre as drogas a partir da Educação Popular. Para atingir este propósito, metodologicamente, apoia-se em dois pressupostos: 1) uma revisão da literatura em língua portuguesa, espanhola, francesa e inglesa; 2) um estudo empírico realizado no Uruguai, em Montevidéu, no contexto da implementação da política de descriminalização e venda legal de cannabis, focando, entre outros aspectos, a dimensão educativa da política. Alguns dos seus resultados são, por exemplo: 1) a abordagem da Educação Popular sobre as drogas requer um escrutínio sócio-histórico delas no contexto da relação sociedade e desvio social; 2) a Educação Popular demanda uma mudança discursiva na forma de se referir às pessoas que usam drogas, na perspectiva de superar a linguagem estigmatizada; 3) o trabalho socioeducativo no âmbito das ações de redução de danos, sob a Educação Popular, implica conhecimentos interdisciplinares. Dentre as conclusões, afirma-se que o estudo das drogas necessita ser situado analiticamente no plano social, e não na esfera dos fatores individuais, que tendem a definir o seu uso como uma patologia estritamente pessoal.

Palavras-chave: Educação Popular. Drogas. Políticas. Sociedade.

\section{KNOWLEDGE ON THE MARGINS, OUTSIDERS AND CHALLENGES TO POPULAR EDUCATION: AN APPROACH ABOUT DRUGS AND SOCIO-EDUCATIONAL WORK}

Abstract: This paper is the result of a larger postdoctoral research. It aims to develop an analysis in the sense of presenting a perspective of approach on the drugs according to Popular Education. In this way, methodologically, it is based on two methodological assumptions: 1) a review of literature in Portuguese, Spanish, French and English; 2) an empirical study carried out in Uruguay, in Montevideo, in the context of implementation of the decriminalization and sale policy of cannabis, focusing, among other aspects, on its educational dimension. Some of its results are, for example: 1) Popular Education's approach about drugs must carry out a socio-historical

\section{POLÊM!CA | LABORE (S:}

Polêmica - Revista Eletrônica da Uerj - Rua São Francisco Xavier, 524, $1^{\circ}$ andar bloco D, sl.1001 • Tels.: +55 21 2334-4088 / 4087 • http://www.e-publicacoes.uerj.br/index.php/polemica/index http://www.labore.uerj.br • laboreuerj@yahoo.com.br 
scrutiny of them in the context of the relationship society and social deviance; 2) Popular Education requires a discursive change in the way of referring to people who use drugs, to overcome the stigmatized language; 3) Socioeducational work in the field of the harm reduction actions, according to Popular Education, demands interdisciplinary knowledge. Among the conclusions, it is affirmed that the study of the drugs must be analytically situated in the social plane, instead of being in the sphere of individual factors, which tend to define its use as a strictly personal pathology.

Keywords: Popular Education. Drugs. Policies. Society.

\section{Introdução}

Uma abordagem sobre a Educação Popular que tenha como perspectiva colocá-la diante das demandas da formação, da pesquisa e da intervenção oriundas dos desafios das temáticas contemporâneas, como é o caso das drogas, requer, antes de tudo, que se reponha a sua dimensão sócio-histórica. Esta é uma condição imprescindível para que ela seja revestida de base conceitual e, assim, possa responder consistentemente às questões que pautam o debate atual a respeito da relação entre sociedade e intervenção educativa.

Como é convencional proceder quando se procura captar as dimensões sócio-históricas (BURKE, 1980), deve-se começar buscando a própria genealogia da Educação Popular. Parece ser razoavelmente fiável afirmar que o que se tem sublinhado sob esta denominação é fundamentalmente um fenômeno surgido na América Latina ${ }^{1}$, tendo primórdios fortemente radicados na segunda metade do século XX no Brasil ${ }^{2}$. O seu desenvolvimento está vinculado, entre outros, aos seguintes fatores:

a) A constituição do Movimento de Cultura Popular (MCP) em Recife, em 1960, por estudantes universitários, artistas e intelectuais, em ação conjunta com a prefeitura da cidade, sendo prefeito à época Miguel Arraes. O MCP foi organizado sob a influência de fontes como o movimento francês Peuple et Culture $^{3}$ e tinha as suas atividades

\footnotetext{
${ }^{1}$ No entanto, não se deve desconsiderar a influência de fatores do contexto europeu, como as ações socioculturais, sociopolíticas e a constituição das universidades populares.

2 Digo primórdios fortemente radicados no Brasil, e não "os primórdios" - o que daria a ideia de fonte única e absoluta -, pois evidentemente não se deve ignorar, por exemplo, as raízes argentinas da Educação Popular, sendo imprescindível que as análises tenham em atenção, entre outras contribuições históricas, o papel do Departamento de Extensão Universitária da Universidade de Buenos Aires (DEU) e o trabalho de Amanda Toubes. Ver Toubes (1961) e Toubes et. al. $(2006,2001)$.

${ }^{3}$ Movimento fundado por universitários e militantes da Resistência Francesa diante da ocupação nazista durante a Segunda Guerra Mundial. Os seus principais fundadores foram Joffre Dumazedier, Paul Lengard, Bemnigno Cáceres y José Rovan. Peuple e Culture, além de apostar nos recursos da poesia, do teatro, do canto e da arte, da história e da filosofia, procurava desenvolver uma formação geral, como assinalou Dumazedier et. al. (2001), voltada à aprendizagem das seguintes dimensões: observação, leitura da realidade, análise, formas de expressão individual e em grupo; ou seja, tratava-se, segundo Dumazedier, de ensinar a pensar cientificamente partindo de fatos que se deveria enfrentar na prática. Esse modo de proceder era valorizado pela Resistência Francesa no combate clandestino diário que tinha que travar contra os nazistas.
}

\section{POLÊM!CA | LABORE (S:}

Polêmica - Revista Eletrônica da Uerj - Rua São Francisco Xavier, 524, $1^{\circ}$ andar

bloco D, sl.1001 • Tels.: +55 21 2334-4088/4087 • http://www.e-publicacoes.uerj.br/index.php/polemica/index http://www.labore.uerj.br • laboreuerj@yahoo.com.br 
orientandas fundamentalmente para o desenvolvimento de ações socioculturais, a conscientização da população e a alfabetização de adultos. Figuravam entre os seus integrantes Ariano Suassuna e Francisco Brennand. Foi extinto pelo golpe civil-militar de 1964;

b) O método de alfabetização de adultos criado por Paulo Freire, relacionando educação e política, marcado por uma dupla operacionalização (FREIRE, 1987; 1982; 2000). Ou seja, inicialmente, um momento preliminar de estudo da realidade - à maneira históricosociológica - em que será desenvolvida a alfabetização, pesquisando, por exemplo, os modos de vida da localidade. Em seguida, o segundo momento com os passos de execução do método propriamente dito, isto é: i) levantamento do universo vocabular dos grupos com os quais se trabalhará; ii) escolha das palavras selecionadas do universo vocabular pesquisado; iii) criação de situações existenciais típicas do grupo de educandos que se tem em foco; iv) elaboração de fichas-roteiro para auxiliar os coordenadores de debate no trabalho que desenvolverão; v) elaboração de fichas com a decomposição das famílias fonêmicas correspondentes aos vocábulos geradores;

c) A criação do Movimento de Educação de Base (MEB), em 1961, vinculado à Igreja Católica através da Confederação Nacional dos Bispos do Brasil (CNBB), que adotou a perspectiva sustentada por Paulo Freire;

d) A fundação do Centro de Cultura Popular (CPC) da União Nacional dos Estudantes (UNE), em 1962, concebendo a reflexão racional e a arte como dispositivos indutores da transformação social, tendo entre os seus integrantes, por exemplo, o sociólogo Carlos Estevam Martins, o cineasta Carlos Diegues e o poeta Ferreira Goulart.

Assim como ocorreu com o Movimento de Cultura Popular, também o CPC foi extinto depois do golpe civil-militar de 1964. Por outra parte, dos referidos entes organizativos, o MEB foi o único a sobreviver durante a ditadura, principalmente em decorrência da sua ligação com a Igreja Católica, e assim continuou com as suas atividades, conforme a adequação e os condicionamentos do novo contexto ${ }^{4}$.

\footnotetext{
${ }^{4}$ Provavelmente daí se tenha derivado uma visão de Educação Popular com ênfase mais nas dimensões relacionais da ação educativa, e menos nos conteúdos necessários requeridos pela esfera cognitiva do processo de ensinoaprendizagem, o que parece ser atualmente uma orientação com forte predomínio no âmbito de determinadas perspectivas freireanas - sem se avaliar, no entanto, os efeitos indevidos que podem resultar disso. Na realidade, fatos como este possivelmente têm conexão com as diferenças que estiveram na origem da Educação Popular no
}

\section{POLÊM!CA $\mid$ LABORE}


De toda forma, no marco original da Educação Popular, há um núcleo programático que a distingue da educação formal convencional (LEITE, 2018), na medida em que é dotado de premissas metodológicas (conhecer a realidade), cognitivas (produzir conhecimentos), políticas (intervenção na realidade, transformação social) e de sociabilidade (busca de novas formas de relações humanas). Ainda que o predomínio atual das dimensões relacionais na Educação Popular tenha propensão a ignorar estas premissas - ou, no máximo, incida sobre a última de forma caricaturada -, elas estão inscritas em sua historicidade.

Tendo presente a sua base originária, parece ser possível estabelecer uma periodização da Educação Popular, segundo sublinhado aqui, em três fases: a primeira vai da sua ascensão até ao golpe civil-militar de 1964; a segunda concerne ao período da elaboração e divulgação de suas perspectivas em outros países da América Latina ${ }^{5}$, de 1964 até ao fim do ciclo das ditaduras que tiveram lugar nessa região, fim ocorrido na década de 1980; e a atual fase, que se inicia, sobretudo, ao final da década de $1980^{6}$, com novas pautas e desafios contemporâneos (LEITE, 2018).

Os diferentes fatores que estiveram na origem da Educação Popular, assim como as implicações das suas distintas fases evolutivas, têm gerado uma pluralidade de enfoques e compreensões a seu respeito que chegam até mesmo, pode-se dizer, a se antagonizarem. Dessa forma, como enfatiza Calado (2014), o conceito de Educação Popular torna-se tão amplo que parece aproximar-se de uma panaceia, isto é, nele cabe quase tudo desde que, ao final, se acrescente um qualificativo: popular.

Ir além da mera adjetivação demanda, portanto, um esforço analítico de maior fôlego. Nesse sentido, no caso da relação Educação Popular e drogas, é fundamental escrutinar o próprio conceito de sociedade, tendo em atenção os seus grupos sociais, as relações de poder e a definição de normas. Isso será tratado a seguir, tendo em vista o objetivo deste trabalho, qual seja, desenvolver uma análise no sentido de apresentar uma perspectiva de abordagem sobre as

Brasil, como, por exemplo, no que se refere ao tema do diretivismo e não diretivismo. A propósito deste debate, ver o trabalho de Gonzalez (2011) sobre as concepções de Educação Popular do MEB e do CPC.

${ }^{5}$ Essa segunda fase é um momento em que muitos intelectuais latino-americanos transitaram de um país para outro da região, em decorrência da perseguição movida pelas ditaturas que, em cadeia, ascenderam ao poder em seus diversos países. Dessa forma, desenvolveu-se uma ciência social própria da América Latina, com as suas elaborações sendo disseminadas pelas diversas nações que a constituem, e, nesse contexto, as formulações da Educação Popular também foram difundidas, assim como foram ainda os aportes da Teoria da Dependência.

${ }^{6}$ Possivelmente seja sintomático do novo tipo de pautas e dos novos desafios contemporâneos - por comparação com os anos 1960/1970 -, a experiência que o próprio Paulo Freire viveu à frente da Secretaria Municipal de Educação de São Paulo, a partir de 1989, e da qual se retirou em 1991.

\section{POLÊM!CA $\mid$ LABORE}

Polêmica - Revista Eletrônica da Uerj - Rua São Francisco Xavier, 524, $1^{\circ}$ andar

bloco D, sl.1001 • Tels.: +55 21 2334-4088 / 4087 • http://www.e-publicacoes.uerj.br/index.php/polemica/index http://www.labore.uerj.br • laboreuerj@yahoo.com.br 
drogas a partir da Educação Popular. Metodologicamente, além de uma ampla revisão da literatura, o referente deste propósito é um estudo empírico realizado no Uruguai, em Montevidéu, no contexto da implementação da política de descriminalização e venda legal de cannabis, focando, entre outros aspectos, a dimensão educativa da política.

\title{
Sociedade, normas, desvio social e drogas: uma esfera desafiante à Educação Popular
}

O outsider, conforme categorizou Becker (1963), é alguém que desrespeita as regras estabelecidas, incorrendo, assim, em desvio social; ele é colocado nas margens da sociedade. Ou seja, é alguém que se releva à condição de marginal. Contudo, é preciso considerar que:

\begin{abstract}
A diferença na capacidade de estabelecer regras e de impô-las a outros responde essencialmente a diferenças de poder (legal ou extralegal). Os grupos cuja posição social lhes confere armas e poder para fazê-lo estão em melhores condições de impor as suas regras. As distinções de idade, gênero, etnia e classe estão relacionadas com as diferenças de poder, que, por sua vez, explicam o grau em que cada um desses grupos é capaz de impor as suas regras aos outros (BECKER, 1963, p. 17-18).
\end{abstract}

Infere-se então que o outsider é produzido socialmente. Dessa maneira, pode-se assinalar que o desvio não é simplesmente uma tipificação presente em determinadas formas de comportamentos e ausente em outras. Ele é mais o produto de um processo que envolve o modo como as pessoas (re)agem diante do "infrator", pois:

\begin{abstract}
O mesmo comportamento pode constituir, em um determinado momento, uma infração à norma, e em outro momento, não; pode ser uma infração se é cometido por uma determinada pessoa, e por outra, não; e algumas normas podem ser violadas com impunidade, e outras, não. Em síntese, o fato de que um ato seja desviado ou não depende, em parte, da natureza do ato em si (vale dizer, se viola ou não uma norma) e, em parte, da resposta [reação] dos demais (Ibidem, p. 14).
\end{abstract}

Para além das ambivalências mais diretamente relacionadas às relações de poder que marcam a definição do ato desviado e a etiquetagem de alguém como um outsider, o caso de que se ocupa este trabalho, o das drogas, é bastante ilustrativo da dualidade que caracteriza a atribuição de imputações no tocante à designação do que é permitido e proibido, sobretudo quando se tem em conta a variável drogas lícitas e drogas ilícitas.

Quer dizer, existem diversas drogas cujo consumo é legal/lícito, sendo elas, então, socialmente aceitas. As principais são as bebidas alcóolicas ${ }^{7}$, o tabaco e a cafeína. No que diz

\footnotetext{
${ }^{7}$ A estabilidade da legitimação social do álcool faz com que, em geral, ele não seja comparado cotidianamente com outras drogas (ilícitas) em termos de efeitos problemáticos. No entanto, isso não logra ocultar o "inusitado",
}

\section{POLÊM!CA | LABORE (}

Polêmica - Revista Eletrônica da Uerj - Rua São Francisco Xavier, 524, $1^{\circ}$ andar

bloco D, sl.1001 • Tels.: +55 21 2334-4088/4087 • http://www.e-publicacoes.uerj.br/index.php/polemica/index

http://www.labore.uerj.br • laboreuerj@yahoo.com.br 
respeito às drogas ilícitas, o consumo não é, por regra geral, aceito, e quem as consumir está sujeito, na maioria dos países, a formas mais ou menos graves de censura penal, além de enfrentar o estigma social.

A dubiedade no contexto de uso é bastante acentuada, pois uma substância é considerada medicamento se for receitada por um médico; fora dessa alçada, é simplesmente uma droga. De igual modo, um adito a um produto adquirido no mercado informal é visto como um drogado; por outro lado, um adito a um produto obtido na relação médica é definido como um paciente (FERNANDES, 2011).

Mesmo existindo essa extrema incongruência no contexto do uso de drogas, o ato de consumir fora do que é considerado o padrão convencional está sujeito a controles sociais que, como ocorre diante do que é concebido como comportamentos desviados, buscam reprimi-lo para sustentar os comportamentos valorizados socialmente. Os controles sociais afetam a conduta individual, em um primeiro momento, através do uso do poder, por via da aplicação de sanções. As condutas em relação as quais se atribui valor positivo são promovidas e as etiquetadas como negativas são castigadas.

A operacionalização desse processo não é levada adiante, em muitas situações, sem o acionamento de variáveis político-ideológicas, e, em muitos casos, são mesmo elas a razão de se considerar um determinado comportamento como desviado e de se rotular quem nele incorre como um outsider. A esse respeito, o caso da cannabis é paradigmático, principalmente quando se considera a posição do governo dos Estados Unidos em perspectiva histórica.

Por exemplo, na década de 1930, a Agência Federal de Narcóticos, sob a direção de Harry J. Anslinger, iniciou uma cruzada contra as pessoas que consumiam cannabis, a partir de pressupostos preconceituosos e enviesados politicamente. Os registros históricos dos posicionamentos de Anslinger na Câmara de Representantes são elucidativos a esse respeito, segundo Gerber os relata: "A maioria dos fumadores de marijuana são negros, hispânicos, músicos de jazz e artistas. Sua música satânica é motivada pela marijuana e seu consumo por parte das mulheres brancas as fazem querer buscar relações sexuais com negros, artistas e outros.”(GERBER, 2004, p. 9).

principalmente quando considerado que, "frente à convalidação social e complacência que o álcool produz, não é possível sustentar consistentemente que reprimir os usuários de drogas ilícitas suponha um critério de tutela da saúde pública ou da saúde social. Bastaria recordar as palavras cirroses hepáticas e delirium tremens, para advertir a incoerência" (NEUMAN, 1991, p. 1). De resto, são inúmeros os delitos associados ao consumo problemático de bebidas alcoólicas, como os referentes ao trânsito.

\section{POLÊM!CA $\mid$ LABORE}

Polêmica - Revista Eletrônica da Uerj - Rua São Francisco Xavier, 524, $1^{\circ}$ andar

bloco D, sl.1001 • Tels.: +55 21 2334-4088 / 4087 • http://www.e-publicacoes.uerj.br/index.php/polemica/index http://www.labore.uerj.br • laboreuerj@yahoo.com.br 
Também na mesma perspectiva, nos anos 1970, se manifestou o presidente Richard Nixon, ao criar a DEA (Agência de Combate às Drogas) e declarar a chamada 'Guerra contra as Drogas'. A posição de Nixon seguiu os passos das manifestações preconceituosas de Anslinger, sendo que, no caso específico do presidente, a tentativa de manipulação políticoideológica foi realçada explicitamente, na medida em que atribuía a existência das drogas a uma 'conspiração esquerdista e comunista'. Grillo (2011, p. 44) registra de forma reveladora as palavras de Nixon nesse sentido: "A homossexualidade, a droga, a imoralidade em geral são inimigas das sociedades fortes. Mas os comunistas e os esquerdistas as estão impulsionando. Estão tentando nos destruir".

Tendo em conta esse tipo de posições, assim como as variáveis implicadas na relação sociedade, regras, desvio e produção de outsiders, e considerando as premissas do núcleo programático da Educação Popular anteriormente enfatizadas (metodológicas, cognitivas, políticas e de sociabilidade), cabe enfatizar que o primeiro imperativo de uma abordagem da Educação Popular sobre as drogas é realizar um escrutínio sócio-histórico das políticas de droga, da gênese/evolução do proibicionismo e da dimensão (geo)política que o tema comporta.

O segundo, por consequência, diz respeito a definir as modalidades específicas do desenvolvimento do trabalho educativo sobre as drogas a partir da ótica da Educação Popular (LEITE, 2018). Considerando os limites de espaço deste trabalho, serão tratados, de forma introdutória, os dois referidos imperativos nas próximas seções.

\section{Drogas, políticas e proibicionismo: uma incursão sócio-histórica}

Os primeiros passos do proibicionismo e da ascensão criminalizadora às drogas remontam ao início do século passado, designadamente com as conferências de Shangai e Haia, realizadas respectivamente em 1909 e 1912, sob o impulso estadunidense (LABROUSSE,

\section{POLÊM!CA $\mid$ LABORE}


2011). Estavam em jogo os interesses em torno do lucrativo comércio do ópio ${ }^{8}$, fato este que chegou a resultar inclusive em guerras envolvendo a Inglaterra e a China ${ }^{9}$.

O empenho dos Estados Unidos na realização das referidas conferências relaciona-se a fatores como o desejo de estreitar relações com a China - buscando beneficiar-se do quadro de confronto existente então entre chineses e países europeus - e intervir no comércio internacional de ópio. Contudo, os interesses político-econômicos em jogo dificultavam a definição de uma agenda para orientar as discussões nas conferências, com isso ficando bastante evidente na de Haia, em 1912. De acordo com Escohotado (1998, p. 628),

Como em Shangai, a Turquia seguiu negando-se a participar, e Áustria-Hungria tampouco compareceu. Inglaterra só queria falar sobre morfina e cocaína, e a Alemanha protestava em nome dos seus poderosos laboratórios, alegando que a Suíça não estava presente e aproveitaria as restrições em seu benefício privado. Portugal defendia a sua indústria de ópio em Macau, e a Pérsia os seus ancestrais cultivos. A Holanda estava implicada no tráfico de ópio e morfina, e produzia milhares de toneladas de coca em Java. A França se encontrava dividida entre os rendimentos provenientes do consumo de opiáceos em Indochina e o temor de ver-se inundada pelos produtos de suas colônias. O Japão foi acusado de introduzir massivamente morfina, heroína e hipodérmicas no território chinês como parte dos seus propósitos invasores, embora tenha negado qualquer vínculo como semelhante coisa. A Rússia tinha uma considerável produção de ópio, mas inferior à de Siam. A Itália, que só compareceu no primeiro dia, colocou como condição para participar que se incluísse o tema do cânhamo, condição rechaçada pela maioria.

\footnotetext{
${ }^{8}$ Conforme assinala Garat (2016, p. 41), "o ópio é resultado do suco da papoula. Seu uso documentado remonta ao Neolítico. É um impecável calmante para dores. O Mediterrâneo e a Mesopotâmia albergaram os cultivos mais antigos. Há cerca de três mil anos antes de Cristo, os sumérios o utilizavam o seu suco. Na Babilônia, em Tebas, Roma e Atenas, entre outras cidades antigas, em seus momentos de esplendor, bebiam-no ou fumavam-no. Os romanos foram os primeiros que o usaram com o objetivo de levar o enfermo a uma morte sem sofrimento. A princípios do século XVIII, as cortes reais europeias utilizavam láudano, uma maceração alcóolica opiada, e outros derivados da papoula para uma variedade de misteres. Com o passar do tempo e a expansão comercial dos impérios, esse remédio passaria a ser comercializado entre os boticários a preços razoáveis, popularizando o seu uso, não só no Velho Continente senão também nos territórios ultramarinos dos reinos europeus durante os séculos XVIII e XIX".

${ }^{9}$ Impulsionado pela Revolução Industrial e tendo uma grande rede de portos a sua disposição, o Império Britânico praticamente monopolizou o comércio mundial de ópio (que obtinha na Índia, então sua colônia). Os ingleses desbancaram os espanhóis no comércio de ópio com a China, e fixaram o produto como moeda de transação comercial, ou seja, obtinham dos chineses sedas, chã, porcelanas e outros bens, e lhes pagavam com ópio. Tratavase de um negócio altamente favorável para o Império Britânico, e extremamente negativo para a China. Ademais, a monarquia chinesa passou a se preocupar com os efeitos que a indução à generalização do consumo de ópio causava. Assim, proibiu o ópio britânico, "o que fez o mercado clandestino crescer. A Companhia das Índias Orientais e, em menor medida, os portugueses continuaram com o contrabando de ópio, apesar de três imperadores distintos [chineses] terem proibido a sua exportação em 1729, 1799 e 1810" (GARAT, 2016, p. 42). Como protesto, em 1839, o governo chinês ordenou a destruição de um carregamento inglês. O Império Britânico considerou o ato uma afronta aos seus interesses comerciais e ordenou a invasão armada da China, dando início a chamada Primeira Guerra do Ópio, tendo como resultado a derrota chinesa e a entrega de Hong Kong aos vencedores. Em 1856, eclodiu uma Segunda Guerra do Ópio, após funcionários da China revisarem um navio inglês (os europeus consideraram que as cláusulas do acordo que colocou fim à Primeira Guerra do Ópio no estavam sendo respeitadas pelo governo chinês). Nessa Segunda Guerra, a Inglaterra teve o apoio da França e da Irlanda. Novamente derrotada, a China se viu obrigada a manter os seus portos abertos aos vencedores e a lhes pagar altas indenizações.
}

\section{POLÊM!CA $\mid$ LABORE}

Polêmica - Revista Eletrônica da Uerj - Rua São Francisco Xavier, 524, $1^{\circ}$ andar

bloco D, sl.1001 • Tels.: +55 21 2334-4088/4087 • http://www.e-publicacoes.uerj.br/index.php/polemica/index http://www.labore.uerj.br • laboreuerj@yahoo.com.br 
A Inglaterra havia sido o principal objeto de debate na Conferência de Shangai, como comercializadora de ópio, e então pressionava para que a Conferência de Haia discutisse também outras substâncias. Os ingleses adotaram como estratégia estabelecer precondições para participar da Conferência de Haia, como incluir no debate a regulação de alcaloides industrializados, a exemplo da morfina e da cocaína (SHEERER, 1993), pois, assim, a política exterior inglesa atendia às reivindicações das suas indústrias farmacêuticas, que tinham os laboratórios alemães como os seus principais concorrentes. A Alemanha não se negou a participar e aceitou as precondições inglesas, mas, com o apoio da Holanda e da França, insistiu na participação de outros países, alegando que só dessa forma a Conferência teria força. Contudo, o propósito alemão, que foi alcançado, era atrasar as discussões. Ao final, alguns países não ratificaram a Convenção de Haia, como a própria Alemanha, França, Bolívia, Colômbia, Peru e os Países Baixos.

A Conferência de Haia foi o primeiro intento do proibicionismo coordenado mundialmente, tendo em conta o ópio e outras drogas, como morfina, heroína e cocaína. A Primeira Guerra Mundial eclodiu antes que a Convenção dela decorrente pudesse ser implementada, mas, ao seu fim, se reivindicou junto à Sociedade das Nações ${ }^{10}$ a sua adoção. Derrotada na Primeira Guerra, a Alemanha foi obrigada a ratificar a Convenção de Haia, que foi anexada ao tratado de rendição em 1919 (Tratado de Versalhes) para assinatura.

Com base na Convenção de Haia, legisladores estadunidenses intensificaram as iniciativas para instituir e consolidar o proibicionismo no país. O senador Francis Burton Harrison apresentou um projeto de lei, que foi aprovado, criando um sistema terapêuticopolicial, pois atava o segmento médico à lei através das diretrizes do Narctotic Control Department, tendo em perspectiva condicionar o uso de ópio, morfina e cocaína a fins médicos (RODRIGUES, 2004). Depois de recusar a constitucionalidade da lei, a Corte Suprema a validou em 1919. Também neste ano, o senador republicano Andrew Volstead aprovou o seu projeto colocando fim ao comércio de bebidas alcóolicas. Foi o chamado Volstead Act, conhecido popularmente como Lei Seca. Entre as organizações que apoiaram esta iniciativa,

${ }^{10}$ Instituição que precedeu à Organização das Nações Unidas (ONU).

\section{POLÊM!CA $\mid$ LABORE}


consta a $K u$ Klux Klan, que havia sido reorganizada pelo maçom e predicador metodista William Joseph Simmons, em $1915^{11}$ (BLANRUE, 2005).

Assumindo um papel de liderança nas políticas de drogas e pretendendo expandir a todo o mundo as suas diretrizes internas, o governo dos Estados Unidos defendeu a realização de uma nova conferência sobre o tema, sob os auspícios da Sociedade das Nações. Assim, em novembro de 1924, na sede dessa, em Genebra/Suíça, se iniciaram as discussões que resultaram na II Convenção Internacional do Ópio. A Conferência foi marcada por significativas divergências, com os representantes dos Estados Unidos manifestando insatisfação com os rumos dos debates e com o fato de que as suas propostas não estavam tendo a aceitação que o seu governo pretendia. Além disso, alguns países produtores de cocaína não estavam de acordo com as medidas restritivas propostas, o que desencadeou acentuados desencontros, fazendo com que a Conferência fosse suspensa até 1925, o que motivou a retirada dos Estados Unidos do evento. Apesar dessa discrepância, a Convenção de Genebra adotou as propostas estadunidenses de penalização e criou o primeiro órgão multilateral responsável pela política mundial de drogas, isto é, o Comitê Central Permanente, tendo como principal atribuição realizar a fiscalização do mercado internacional das substâncias monitoradas pela Convenção (ESCOHOTADO, 1998). A marijuana foi incluída na lista das substâncias monitoradas.

Nesse contexto, os Estados Unidos se consolidaram como referência internacional nas decisões das políticas sobre drogas. Em 1930, Harry Jacob Anslinger assumiu o Federal Bureau of Narcotic e se empenhou na organização de uma nova conferência para limitar a fabricação de drogas narcóticas. Em tal ambiente, Anslinger vislumbrou o combate à marijuana e a sua total criminalização como uma nova forma de motivação e de obtenção de apoio ao discurso proibicionista, diante do fracasso da Lei Seca, objetivando obter recursos para levar adiante a 'cruzada'.

Depois de ter alcançado o seu propósito nos Estados Unidos, Anslinger assumiu um papel central na Conferência de 1931, realizada também em Genebra e no âmbito da Sociedade das Nações. Desse modo, foram aprovadas regras mais rígidas e se estabeleceu uma base mais concreta para impulsionar a expansão internacional do proibicionismo. A Convenção de 1931 tratou fundamentalmente de restringir as drogas à escala do comércio medicinal e, ao mesmo

\footnotetext{
${ }^{11}$ Organização racista surgida na segunda metade do século XIX, depois da Guerra de Secessão, a Ku Klux Klan despertou reações que levaram ao seu declínio. Porém, em 1915, William Joseph Simmons a reorganizou. Tratouse do que ficou conhecido como a segunda Ku Klux Klan.
}

\section{POLÊM!CA $\mid$ LABORE}

Polêmica - Revista Eletrônica da Uerj - Rua São Francisco Xavier, 524, $1^{\circ}$ andar

bloco D, sl.1001 • Tels.: +55 21 2334-4088 / 4087 • http://www.e-publicacoes.uerj.br/index.php/polemica/index http://www.labore.uerj.br • laboreuerj@yahoo.com.br 
tempo, desenvolver um padrão de medidas punitivas. Nesse sentido, recomendou que os países deveriam reunir informações sobre as suas necessidades de consumo medicinal, tendo em conta, por exemplo, no caso do ópio, a transformação do produto bruto em derivações, a partir do cálculo das necessidades anuais e da quantidade de reservas de estoque (ESCOHOTADO, 1998).

A Conferência de 1931 também exortou os países signatários a estabelecer uma política doméstica tendo como perspectiva a criação de estruturas de controle e fiscalização do uso e comércio de drogas consideradas legais, assim como de repressão às drogas ilegalizadas. $\mathrm{O}$ enfoque estadunidense sobre política de drogas estava se tornando hegemônico, e assim se abriu o caminho para o aprofundamento de medidas proibicionistas cinco anos depois, com a realização da Conferência de 1936, novamente em Genebra. Ou seja, “o caminho para a institucionalização de medidas penais, no plano internacional, começou a ser aberto em 1931. Cinco anos depois, a tendência se concretiza, com a aprovação de medidas penais para o tráfico e consumo de drogas controladas" (RODRIGUES, 2004, p. 58).

Com a eclosão da Segunda Guerra Mundial, as discussões sobre as drogas entre os países passaram por um interregno. No entanto, pouco tempo após o final do conflito, em 1946, já sob a convocatória da Organização das Nações Unidas (ONU), firmou-se um protocolo que reconhecia e atualizava os acordos anteriores. Em 1948 e 1953, firmaram-se protocolos em Paris e Nova Iorque respectivamente.

Contudo, foram protocolos pontuais, reforçando a perspectiva proibicionista, como, por exemplo, restringindo a produção de opiáceos na fonte. O evento que viria a marcar as políticas de drogas na segunda metade do século XX (até hoje), como já enfatizado, teve lugar em 1961, com a Convenção Única da ONU sobre Estupefacientes. Composta por cinquenta e um artigos, a Convenção de 1961 relaciona os estupefacientes, classificando-os segundo as suas propriedades (ONU, 1961). Em síntese, pode dizer-se que as linhas básicas da Convenção são as seguintes: estabelece as medidas de controle e fiscalização; disciplina o procedimento para a inclusão de novas substâncias que devam ser controladas; institui a competência das Nações Unidas em matéria de vigilância interna; descreve as medidas que devem ser adotadas em nível nacional para a ação contra o tráfico, buscando iniciativas coordenadas com os Estados; apresenta tipificações penais, recomendando que o tráfico, a produção, a posse e o consumo de drogas em desacordo com a Convenção sejam punidos rigorosamente.

\section{POLÊM!CA $\mid$ LABORE}


Os eventos internacionais posteriores sobre política de drogas e as ações da ONU seguem o marco da Convenção de 1961 (UNODC, 2013). Desse modo, em 1971, em Viena, firmou-se um acordo a respeito de substâncias psicotrópicas, para controlar a preparação, o uso e o comércio; em 1972, assinou-se o Protocolo de Emendas à Convenção Única, no sentido, por exemplo, de alterar a composição e as funções do Órgão Internacional de Controle de Estupefacientes; em 1977, na Conferência Internacional sobre o Abuso de Drogas e Tráfico Ilícito, buscou-se definir novas medidas para combater o tráfico; em 1988, a Convenção contra o Tráfico Ilícito de Estupefacientes e Substâncias Psicotrópicas propôs o fortalecimento do controle de precursores químicos que podem ser utilizados na preparação de substâncias psicotrópicas; em 1998, a Sessão Especial da Assembleia Geral da ONU sobre Drogas elaborou uma Declaração com orientações exortando os países a desenvolver estratégias enfocadas conjuntamente na redução da oferta e da demanda, como forma de realizar o combate global às drogas.

Conforme demonstram as notas sócio-históricas realçadas, o governo dos Estados Unidos tomou em suas mãos a política internacional de drogas, principalmente depois da Segunda Guerra, adotando a perspectiva de uma luta global contra as chamadas drogas ilícitas. Na década de 1970, o presidente Richard Nixon declarou o ataque total, como já referido.

A opção bélica na forma de tratar a questão das drogas levou o governo estadunidense a criar estruturas operacionais específicas para este fim e a adotar uma série de encaminhamentos, principalmente na América Latina. Isso se traduziu, por exemplo, no lançamento de um agressivo plano contra as drogas através das suas embaixadas nos países latino-americanos. A partir de 1970, todos as nações do hemisfério adequaram as suas legislações internas à Convenção Única de Estupefacientes de 1961 e à de 1971 (Viena). Para monitorar pontos de produção e comercialização de drogas no mundo, Nixon criou, em setembro de 1971, o Cabinet on Committee for International Narcotic Control. Todavia,

Foi a DEA (Drug Enforcement Administraion), nascida em 1973, que criou um verdadeiro cordão internacional para coordenar as investigações e a repressão ao comércio de drogas ilícitas com os governos e as polícias locais de todo o mundo. As autoridades estadunidenses advertiam os países do sul que, ainda que não registrassem consumo elevado de drogas em seus territórios, isso iria mudar em pouco tempo, e, por essa razão, nada melhor do que cortar cooperativamente pela raiz o comércio de drogas. Em 1974, a DEA montou o seu primeiro grande operativo contra a Jamaica e um ano depois voltou ao México na chamada Operação Condor, eliminado plantações de cannabis. A plantação foi transferida para La Guajira colombiana. Aos poucos eram 70.000 as famílias colombianas que viviam do cultivo, obtendo rendimentos seis

\section{POLÊM!CA $\mid$ LABORE}

Polêmica - Revista Eletrônica da Uerj - Rua São Francisco Xavier, 524, $1^{\circ}$ andar

bloco D, sl.1001 • Tels.: +55 21 2334-4088/4087 • http://www.e-publicacoes.uerj.br/index.php/polemica/index

http://www.labore.uerj.br • laboreuerj@yahoo.com.br 
vezes superiores aos do café [...]. O tráfico continuou aumentando (GARAT, 2016, p. 70).

A Colômbia possivelmente é um dos países onde são manifestados de forma mais evidente os interesses estratégicos da política antidroga estadunidense e o seu caráter geopolítico. O país tem costas sobre o Pacífico e o Caribe. Além disso, empresas petrolíferas dos Estados Unidos operam na Colômbia e o governo norte-americano equipa e treina, através das suas companhias privadas de segurança, soldados colombianos para proteger $770 \mathrm{~km}$ do oleoduto Caño Limo-Coveñas (LABROUSSE, 2011). É esta importância geoestratégica que explica que o país do Norte tenha feito 'vista grossa' e ignorado “os vínculos dos partidos políticos que apoiavam o presidente [Álvaro] Uribe com os paramilitares ligados ao tráfico de drogas" (Ibidem, p. 105). Ou seja, paradoxo e verdade ao mesmo tempo: a potência que promove o discurso do combate ao tráfico de drogas aceita a sua existência em nome dos seus interesses geopolíticos.

Apesar da contradição e hipocrisia das principais potências ocidentais - envolvendo os seus interesses, as drogas e a obtenção de vantagens políticas e econômicas -, a imagem que tem sido difundida - do continente americano para o mundo - é que a criminalidade associada à droga e à corrupção é de responsabilidade exclusiva das nações da região que têm identidade latina. Contudo, por outro lado, esse fato também reflete o profundo fracasso que tem sido a política proibicionista e a chamada 'Guerra contra as Drogas', que não têm impedido o crescimento do consumo, gerando ainda um efeito adicional e perturbador: o aumento da violência e a preparação de terreno para a disseminação de outras modalidades de crime. A propósito do referido fracasso, na Sessão Especial da Assembleia Geral das Nações Unidas sobre Drogas (UNGASS), de 1998, foi definido um marco para levar adiante uma ampla redução do consumo mundial de drogas nos dez anos seguintes. Ao final do período, em 2008, no entanto, isso não se verificou, conforme pode ser constatado na tabela a seguir.

$\underline{\text { Tabela - 1: Consumo mundial de algumas drogas (1998-2008) }}$

\begin{tabular}{c|l|l|l}
\hline & Opiáceos & Cocaína & Cannabis \\
\hline 1998 & 12.9 milhões & 13.4 milhões & 147.4 milhões \\
\hline 2008 & 17.35 milhões & 17 milhões & 160 milhões \\
\hline$\%$ de Aumento & $34,5 \%$ & $27 \%$ & $8,5 \%$ \\
\hline
\end{tabular}

Fonte: Adaptado de Global Commission on Drug Policy (2011).

\section{POLÊM!CA $\mid$ LABORE}


O escrutínio sócio-histórico aqui realizado das políticas de drogas, da gênese/evolução do proibicionismo e da dimensão geopolítica que a questão das drogas comporta, como primeiro imperativo para habilitar a abordagem da Educação Popular a respeito, proporciona, ao mesmo tempo, subsídios analíticos básicos a serem incorporados pelo segundo imperativo. Ou seja, conforme foi antes realçado, o imperativo que se refere às modalidades específicas do desenvolvimento do trabalho educativo sobre drogas a partir da ótica da Educação Popular.

\section{Para além do discurso proibicionista sobre drogas: modalidades de abordagem da Educação Popular}

Dentre os subsídios analíticos proporcionados pelo escrutínio sócio-histórico realizado no imperativo anterior, dois são centrais, cabendo serem destacados neste segundo imperativo como forma de lastrear a justificativa e a fundamentação das modalidades de abordagem da Educação Popular a respeito das drogas. Isto é, eles são: i) a evidência de que a Guerra contra as Drogas, alimentada pelo discurso proibicionista, fracassou; ii) a demonstração empírica de que a questão das drogas comporta uma dimensão política e está condicionada pelas disputas que envolvem as relações de poder.

Desse marco decorre que é imprescindível ir além do discurso proibicionista sobre as drogas, superando a ação bélica como dispositivo operacional principal no enfrentamento do tema, e, por outro lado, desvendando as implicações - em termos de poder - ocultamente contidas no modo tradicional de enfocar as drogas e definir as suas políticas. Dentre outros, estes são balizadores centrais a serem tidos em atenção pelas modalidades da Educação Popular no desenvolvimento da abordagem a respeito do trabalho educativo sobre as drogas. A seguir, serão consideradas algumas dessas modalidades.

A primeira concerne à própria linguagem utilizada, quer dizer, refere-se à mudança no tipo de linguagem estigmatizada que geralmente é empregada, que cria, conforme o conceito sociológico formulado por Cohen (1987), o que se pode chamar de pânico moral. A linguagem usada quando se fala de pessoas que consomem drogas (ilícitas) tem um forte impacto na maneira como as demais pessoas e a sociedade em geral as veem, bem como no modo como elas próprias formam o seu autoconceito. Nesse sentido, os meios de comunicação têm uma imensa influência a respeito do modo como a população percebe as drogas. A opinião pública

\section{POLÊM!CA $\mid$ LABORE}


e as representações difundidas pela mídia sobre o consumo de drogas reforçam-se mutuamente, uma vez que são induzidas pela reprodução do estigma.

Termos em geral usados - como drogado - são alienantes e definem as pessoas limitando-as tão somente ao consumo de uma substância, e assim as concebem como "outros indivíduos à parte da sociedade", moralmente defeituosos e inferiores (os outsiders, conforme a abordagem desenvolvida anteriormente).

A estigmatização tem, de imediato, dois efeitos perversos. Isto é, quanto mais a sociedade estigmatiza e repugna as pessoas que usam drogas ilícitas, menos oportunidades de tratamento ao consumo problemático são oferecidas; da mesma forma, o estigma distancia as pessoas que necessitam de ajuda dos serviços disponíveis.

Mudar as percepções sobre as drogas e as pessoas que as usam requer mudar a forma de se referir a elas. Desse modo, trata-se de uma posição a ser efetivamente assumida pela abordagem da Educação Popular a seu respeito. O quadro a seguir oferece uma referência de orientação discursiva nesse processo de mudança ${ }^{12}$, e pode marcar uma diferença relevante na maneira de a Educação Popular enfocar as drogas.

Quadro - 1: Termos recomendáveis e não recomendáveis na abordagem sobre drogas

\begin{tabular}{|l|l|}
\hline \multicolumn{1}{|c|}{ Expressões a evitar } & \multicolumn{1}{c|}{ Expressões a utilizar } \\
\hline Usuário de drogas & Pessoa que usa drogas \\
\hline $\begin{array}{l}\text { Adito, abusador de drogas, drogado, } \\
\text { maconheiro, etc. }\end{array}$ & $\begin{array}{l}\text { Pessoa com dependência às drogas, pessoa com uso } \\
\text { problemático de drogas, pessoa que usa drogas } \\
\text { (quando o uso não é problemático) }\end{array}$ \\
\hline Viciado em drogas & Desordem por uso de substâncias; uso problemático \\
\hline Adito às drogas & Tem uma desordem com drogas \\
\hline Limpo & Abstêmio; pessoa que deixou de usar drogas \\
\hline Contaminado & Positivo ao uso de substâncias \\
\hline $\begin{array}{l}\text { Lutar, guerrear contra as drogas (e outros } \\
\text { termos violentos) }\end{array}$ & Abordar as drogas, gerir a questão das drogas \\
\hline Narcosalas; salas de injetar-se; picaderos & Salas de consumo supervisado \\
\hline Ex-adito, adito reformado & $\begin{array}{l}\text { Pessoa em recuperação, pessoa em recuperação a longo } \\
\text { prazo }\end{array}$ \\
\hline Usuário de drogas injetáveis & Pessoa que se injeta drogas \\
\hline Terapia de reposição de opioides & Terapia de substituição de opioides \\
\hline
\end{tabular}

Fonte: Elaborado com base em The Associated Press (2017).

A mudança de orientação discursiva é, portanto, uma condição sine qua non para que o tema das drogas seja tratado com o devido equilíbrio. Ao assumir essa mudança como uma das

12 Trata-se de um marco de orientação discursiva a ser realçado nas áreas de atuação que têm interface com as drogas, principalmente nas esferas da educação e da saúde. O quadro é apenas uma amostra, um exemplo preliminar, da mudança discursiva requerida.

\section{POLÊM!CA $\mid$ LABORE}

Polêmica - Revista Eletrônica da Uerj - Rua São Francisco Xavier, 524, $1^{\circ}$ andar

bloco D, sl.1001 • Tels.: +55 21 2334-4088/4087 • http://www.e-publicacoes.uerj.br/index.php/polemica/index http://www.labore.uerj.br • laboreuerj@yahoo.com.br 
suas modalidades na abordagem da questão, a Educação Popular chancela-se como enfoque analítico credenciado a respeito e como dispositivo pertinente de intervenção teórico-prática (LEITE, 2018).

Uma segunda modalidade a ser assumida pela mesma concerne à alternativa da redução de danos, como dispositivo de trabalho socioeducativo no contexto do uso problemático de drogas, e, também, como aposta social para que sejam formuladas políticas sob essa ótica. Para tanto, é fundamental que esteja definido adequadamente, no âmbito da Educação Popular, o que se entende por redução de danos. Nesse sentido, em princípio, importa indagar sobre os danos decorrentes da existência de mercados ilegais e não regulados de drogas ${ }^{13}$, para então se definir princípios e ações para o trabalho socioeducativo em função de sua redução. O quadro a seguir apresenta um panorama dos mesmos.

Quadro - 2: Classificação de danos decorrentes de mercados de drogas ilegais e não regulados

\begin{tabular}{|c|c|}
\hline Contexto & Danos \\
\hline Saúde e segurança pessoal & $\begin{array}{l}\text { - Mortes } \\
\text { - Acidentes no trabalho } \\
\text { - Violências interpessoais diversas }\end{array}$ \\
\hline Social & $\begin{array}{l}\text { - Delinquência organizada } \\
\text { - Delinquência comum } \\
\text { - Degradação urbana } \\
\text { - Perda de espaços públicos } \\
\text { - Insegurança cidadã (objetiva e subjetiva) } \\
\text { - Estigmatização de minorias } \\
\text { - Colapso/ineficiência do sistema penal } \\
\text { - Mais controle/repressão sobre populações específicas }\end{array}$ \\
\hline Econômico & $\begin{array}{l}\text { - Enriquecimento ilícito } \\
\text { - Evasão fiscal } \\
\text { - Fuga de capitais } \\
\text { - Conluio com empresas ilegais } \\
\text { - Custos bilionários da repressão }\end{array}$ \\
\hline Político & $\begin{array}{l}\text { - Corrupção e participação de funcionários públicos em atos ilícitos } \\
\text { - Deslegitimação institucional } \\
\text { - Violações dos direitos humanos e das liberdades civis } \\
\text { - Narcodiplomacia }\end{array}$ \\
\hline Cultural & $\begin{array}{l}\text { - Sexismo } \\
\text { - Lei do mais forte } \\
\text { - Desvalorização da educação como canal de mobilidade social, } \\
\text { abandono escolar, cultura do crime }\end{array}$ \\
\hline
\end{tabular}

Fonte: Elaboração própria baseada em Zaitch (2009).

${ }^{13}$ Considerando ademais que, em nível de consumo, "parte dos danos e riscos presentes estão ligados à natureza mesma das substâncias e à forma como elas são consumidas" (ZAITCH, 2009, p. 63).

\section{POLÊM!CA $\mid$ LABORE}


Parte dos danos descritos no Quadro 2 requerem ser considerados a partir das políticas de drogas mais amplas, onde se coloca a necessidade de discutir a superação do proibicionismo e a regulação do mercado ilegal de drogas. Do ponto de vista do trabalho socioeducativo específico, sob a perspectiva da Educação Popular, impõe-se levar adiante ações em três dimensões, conforme a descrição do Quadro 3.

Quadro - 3: Trabalho socioeducativo de redução de danos sob a perspectiva da Educação Popular

\begin{tabular}{|c|c|}
\hline Dimensões & Ações \\
\hline Promoção dos direitos humanos & $\begin{array}{l}\text { - Defender o garantismo nos trâmites judiciais, penais e } \\
\text { processuais em geral, ou seja, o respeito ao devido } \\
\text { processo legal. } \\
\text { - Rejeitar estados de exceção, violação dos direitos } \\
\text { individuais e a tortura. } \\
\text { - Repelir a aplicação da pena de morte. }\end{array}$ \\
\hline Construção de aportes interdisciplinares & $\begin{array}{l}\text { - Superar as abordagens fragmentadas sobre as drogas, } \\
\text { que geralmente se apoiam apenas numa área científica. } \\
\text { - Produzir enfoques com evidência científica no sentido } \\
\text { de desconstruir a retórica moral e ideológica das } \\
\text { cruzadas antidrogas, principalmente a sua "missão" } \\
\text { politicamente rentável aos seus patrocinadores, ao } \\
\text { combinar um alto grau de discurso populista, o } \\
\text { financiamento de uma massiva casta de supostos } \\
\text { especialistas, funcionários de captura/apreensão e } \\
\text { operações espetaculosas com a cobertura da mídia. }\end{array}$ \\
\hline $\begin{array}{l}\text { Intervenção no contexto da educação } \\
\text { formal }\end{array}$ & $\begin{array}{l}\text { *Preliminarmente, ter presente dois postulados, } \\
\text { inclusive na contracorrente de versões laudatórias da } \\
\text { Educação Popular, quais sejam: } \\
\text { 1) A Escola, em meios sociais de alta vulnerabilidade e } \\
\text { vácuo das instituições, ainda é provavelmente a única } \\
\text { instituição oficial a se fazer presente, detendo (também } \\
\text { ainda) algum respeito material e simbólico. No mais, } \\
\text { prevalece a deslegitimação institucional, a } \\
\text { criminalidade e a sua lógica. Portanto, faz-se necessário } \\
\text { repelir os discursos que desprezam a Escola, sob as mais } \\
\text { diversas justificativas, como, por exemplo: 'é uma } \\
\text { instituição tradicional', 'está em crise', 'a educação } \\
\text { ocorre na rua, no mundo, em nome da liberdade' (uma } \\
\text { compreensão enviesada que se apoia numa dicotomia } \\
\text { entre educação formal e não formal e que, muitas vezes, } \\
\text { equivocadamente encontra abrigo na Educação } \\
\text { Popular). } \\
\text { 2) Defesa do ofício docente, tendo-se presente que o } \\
\text { professor é um mediador indispensável no tocante à } \\
\text { socialização escolar e à relação de ensino- } \\
\text { aprendizagem. Isso significa recusar as visões segundo } \\
\text { as quais a função docente vai desaparecer ou então que, } \\
\text { para a aprendizagem ocorrer, não é necessária a } \\
\text { presença de um professor, 'porque as pessoas se educam }\end{array}$ \\
\hline
\end{tabular}

\section{POLÊM!CA $\mid$ LABORE}

Polêmica - Revista Eletrônica da Uerj - Rua São Francisco Xavier, 524, $1^{\circ}$ andar

bloco D, sl.1001 • Tels.: +55 21 2334-4088/4087 • http://www.e-publicacoes.uerj.br/index.php/polemica/index http://www.labore.uerj.br • laboreuerj@yahoo.com.br 


\begin{tabular}{|l|l|}
\hline & $\begin{array}{l}\text { na interação com o mundo' (outra compreensão } \\
\text { enviesada que também, muitas vezes, encontra abrigo } \\
\text { na Educação Popular). }\end{array}$ \\
Partindo destes dois postulados, desenvolver ações no \\
seguinte sentido: \\
- Esclarecer o significado do conceito de drogas, \\
enfocando a construção sócio-histórica da distinção \\
entre drogas lícitas e ilícitas. \\
- Desenvolver atividades na escola, como oficinas, \\
conjuntamente para pais e alunos sobre o tema. \\
- Proporcionar aportes de formação continuada sobre \\
drogas aos professores, tendo como diretrizes o enfoque \\
sócio-histórico a respeito do tema, a noção \\
medicalização da sociedade, a abordagem do campo da \\
saúde coletiva, o conceito de ownership (propriedade de \\
si, autodomínio), etc.
\end{tabular}

Fonte: Elaboração própria, 2018.

A terceira - e última - modalidade de abordagem da Educação Popular acerca das drogas aqui apresentada tem em atenção, em princípio, que o problema do uso de drogas não está centrado nas drogas em si, mas sim na forma de consumo, e designadamente no tipo de vínculo que a pessoa estabelece com as substâncias. Disso resulta que é necessário assumir fortemente a distinção entre uso problemático e não problemático quando se fala de drogas. Nessa perspectiva, diante de situações consideradas de emergência, é relevante que o modo de as enfocar siga alguns passos específicos. Entre estes passos, podem ser destacados os seguintes:

a) Entrevistas individuais - Deverão ser realizadas em um contexto adequado e pautadas de acordo com as condições do ambiente educativo. É importante que, no caso de estudantes, não se vincule - diante deles e de forma reiterativa - o tema do consumo com outros problemas que eventualmente apresentem no âmbito educativo, como as

\section{POLÊM!CA $\mid$ LABORE}

Polêmica - Revista Eletrônica da Uerj - Rua São Francisco Xavier, 524, $1^{\circ}$ andar bloco D, sl.1001 • Tels.: +55 21 2334-4088/4087 • http://www.e-publicacoes.uerj.br/index.php/polemica/index http://www.labore.uerj.br • laboreuerj@yahoo.com.br 
dificuldades no rendimento escolar. O foco deve ser a situação específica em apreço. $\mathrm{Na}$ primeira entrevista, a prioridade é escutar, procurando obter a maior quantidade possível de informações.

b) Operacionalização de providências - Esta fase constitui um processo planejado de acordo com estratégias e objetivos previamente definidos. Efetivamente, as entrevistas devem ser feitas como parte desse processo, obedecendo a uma sequência, e não de forma isolada. Conforme este encaminhamento, deve-se evitar medidas apressadas, sem prévia análise e avaliação. Dessa forma, a entrevista se apresenta como uma instância de busca compartilhada, orientada a equalizar a situação. Deve-se comunicar ao estudante que a sua família precisa ser convocada.

c) Derivação ao âmbito da saúde - Em qualquer etapa do processo, pode ser necessário empreender um encaminhamento ao âmbito da saúde, pelo que então se deve trabalhar de forma coordenada com esse setor.

As modalidades de abordagem da Educação Popular sobre as drogas aqui colocadas não são apenas artefatos de mediação pedagógica, mas também dispositivos de análise que interrogam a realidade que envolve o referido tema, no sentido de desconstruir as categorias de pensamento impensadas a seu respeito, que, como disse Bourdieu (1996), delimitam o pensável e predeterminam o pensado.

\section{Conclusão}

Neste trabalho, procurou-se desenvolver uma análise da relação entre Educação Popular e drogas. Para atingir este fim, inicialmente, foram discutidas as heterogeneidades originárias da Educação Popular e o seu escopo; em seguida, demonstrou-se como a esfera envolvendo a sociedade, as normas, o desvio social e as drogas constitui um quadro desafiante à Educação Popular. Tal quadro levou à realização de uma incursão sócio-histórica a respeito da tríade drogas, políticas e proibicionismo, para então delinear, de forma alternativa, algumas modalidades de abordagem da Educação Popular sobre a questão das drogas. Ou seja, a partir do concatenamento de premissas, buscou-se realizar um percurso analítico fundamentado para apresentar uma perspectiva de enfoque das drogas situada no campo da Educação Popular. A título de notas finais, em decorrência do percurso empreendido, importa enfatizar três considerações.

\section{POLÊM!CA $\mid$ LABORË}


A primeira é que o marco de reflexão no qual a abordagem da Educação Popular sobre as drogas aqui exposta se inscreve coloca de parte as explicações que descrevem o ato de contrariar regras da sociedade, a exemplo de usar determinadas substâncias, como sendo resultado de fatores estritamente individuais, não poucas vezes definidos como patologias absolutamente pessoais. A pesquisa a respeito de tal tema deve ser sobretudo o estudo da construção e reafirmação de conteúdos axiológicos da vida cotidiana. Conforme a discussão desenvolvida no início deste trabalho, o desvio às normas, que coloca a pessoa implicada nas margens da sociedade (o outsider), é expressão dos próprios processos sociais, ou seja, é um produto do 'jogo social' segundo a lógica de poder que configura as relações coletivas.

A segunda consideração diz respeito ao fato de que a abordagem da Educação Popular sobre as drogas chancelada nesta incursão analítica descarta duas atitudes bastante tradicionais, principalmente de muitos agentes públicos, quando está em causa a adoção de alguma política de natureza social que demanda um componente educativo, quais sejam: a) um ponto de vista meramente instrumental que parece entender a educação como uma espécie de tecnologia axiologicamente neutra e aplicável com o único propósito de gerir as questões sociais; b) a percepção da educação apenas como recurso retórico e linha auxiliar para construir consenso em torno de iniciativas a serem implementadas. O que estas visões não têm em conta, e que este trabalho sustenta, é que a educação é um fenômeno que não somente reproduz os parâmetros da socialização instituída, mas também ela própria gera novos tipos de sociabilidades e comportamentos que incidem de modo diferente nas mais diversas esferas sociais, como nas formas de organização familiar, na própria escola, no âmbito político, etc.

Por fim, a concepção de Educação Popular aqui subscrita assume como sendo imperioso analisar a sociedade contemporânea indo além da descrição dos seus aspectos, contradições e problemas, assim como da repetição de proclamações anacrônicas para enfrentar estes últimos. Trata-se de uma concepção que, vislumbrando o novo que a marcha do movimento histórico delineia, tem no seu horizonte a construção de uma sociedade na qual a realidade da diversidade humana - seja pessoal, orgânica, social, de gênero ou étnica - não esteja submetida a uma lógica de poder que criminaliza as diferenças das formas como as pessoas vivem a sua existência e suprime a liberdade no modo de elas conduzirem as suas próprias vidas.

\section{POLÊM!CA $\mid$ LABORE}




\section{Referências}

ASSOCIATED PRESS. The Associated Press Stylebook 2017 and Briefing on Media Law. New York: AP, 2017.

BECKER, Howard S. Outsiders: studies in sociology of desviance. New York: The Free Press, 1963.

BURKE, Peter. Sociologia e história. Lisboa: Afrontamento, 1980.

BLANRUE, Paul-Eric. As muitas vidas da Ku Klux Klan. Revista História Viva, [S.1.], n. 21, 2005.

BOURDIEU, Pierre. Lição sobre a lição. Vila Nova de Gaia: Estratégias Criativas, 1996.

CALADO, Alder Júlio F. Educação popular como processo humanizador: Quais protagonistas? In: LEITE, Ivonaldo; PEREIRA, Antonio Alberto. Educação do campo, agroecologia e luta pela terra no Vale do Mamanguape/PB. João Pessoa: Ideia, 2014.

COHEN, Stanley. Folk devils and moral panics: The creation of the mods and the rockers. Oxford: Basil Blackwell, 1987.

DUMAZEDIER, Joffre; CHOSSON, Jean-François; HERFRAY, Charlotte. Acerca del Método Pedagógico del Entrenamiento Mental. Traducción del Francés de Hilda Santos. Buenos Aires: OPFYL, 2001. (Cuadernos de Cátedra Facultad de Filosofía y Letras - UFBA).

ESCOHOTADO, Antonio. Historia general de las drogas. Madrid: Espasa, 1998.

FERNANDES, Luís. Terapias punitivas e punições terapêuticas: o estranho caso do "toxicodependente". In: CUNHA, Manuela Ivone e DURAND, Jean-Yves (Org.). Razões de saúde: poder e administração do corpo vacinas, alimentos, medicamentos. Lisboa: Fim de Século, 2011.

FREIRE, Paulo. A importância do Ato de Ler: em três artigos que se completam. 39. ed. São Paulo: Cortez, 2000 .

FREIRE, Paulo. Pedagogia do Oprimido. 17. ed. Rio de Janeiro: Paz e Terra, 1987.

FREIRE, Paulo. Ação cultural para a liberdade e outros ensaios. Rio de Janeiro: Paz e Terra, 1982.

GARAT, Guillero. Marihuana y otras yerbas: prohibición, regulación y uso de drogas en Uruguay.

Montevideo: Sudamericana, 2016.

GERBER, Rudolph J. Legalizing Marijuana: Drug Policy Reform and Prohibition Politics. Westport, CT: Greenwood Press, 2004.

GLOBAL COMMISSION ON DRUG POLICY. Report of the Global Commission on Drug Policy - War on drugs. 2011. Disponível em:

<http://www.globalcommissionondrugs.org/wpcontent/uploads/2017/10/GCDP_WaronDrugs_EN.pdf >. Acesso em: 20 abr. 2018.

GONZALEZ, Jeferson A. Cultura, educação popular e transformação social nas formulações do MEB e do CPC (1961-1964). 2011. 135 f. Dissertação (Mestrado em Educação). Programa de Pós-graduação em Educação da Faculdade de Educação da Universidade de Campinas (UNICAMP), Campinas, 2011.

GRILLO, Ioan. El narco: Inside Mexico's Criminal Insurgency. Londres: Bloomsbury, 2011.

LABROUSSE, Alain. Geopolítica de las drogas. Montevideo: Trilce, 2011.

\section{POLÊM!CA $\mid$ LABORE (E)}

Polêmica - Revista Eletrônica da Uerj - Rua São Francisco Xavier, 524, $1^{\circ}$ andar

bloco D, sl.1001 • Tels.: +55 21 2334-4088 / 4087 • http://www.e-publicacoes.uerj.br/index.php/polemica/index http://www.labore.uerj.br • laboreuerj@yahoo.com.br 
LEITE, Ivonaldo. De la sociología de la desviación a la sociología de la educación: Drogas, una perspectiva sobre la política uruguaya de regulación del cannabis y las bases hacia el trabajo socioeducativo. 2018. $233 \mathrm{f}$. Informe de Investigación de Postdoctorado (Pós-doutorado em Sociología) - Departamento de Sociología de la Facultad de Ciencias Sociales de la Universidad de la República (UDELAR), Montevideo, 2018.

NEUMAN, Elías. La legalización de las drogas. Buenos Aires: Ediciones Depalma Buenos Aires, 1991.

ONU. Convención Única de 1961 sobre estupefacientes. Nueva York, 1961. Disponível em: <https://www.unodc.org/pdf/convention_1961_es.pdf>. Acesso em: 14 mar. 2018.

RODRIGUES, Thiago. Política e drogas nas Américas. São Paulo: EDUC/FAPESP, 2004.

SHEERER, Sebastian. Estabelecendo o controle sobre a cocaína (1910-1920). In: BASTOS, Francisco I. y Gonçalves, Odair D. (Eds.). Drogas é legal? Rio de Janeiro: Imago, 1993.

TAYLOR, Ian; WALTON, Paul; YOUNG, Jock. La nueva criminología: contribución a una teoría social de la conducta desviada. Buenos Aires: Amorrortu Editores, 1997.

TOUBES, Amanda et. al. Revisión del concepto de educación no formal. UBA: Buenos Aires, 2006.

(Cuadernos de Cátedra de Educación no Formal. Facultad de Filosofía y Letras).

TOUBES, Amanda et. al. La situación de la educación de jóvenes y adultos en la Argentina. Revista Brasileira de Educação, n. 18, p. 22-34, 2001.

TOUBES, Amanda. Un enfoque de la Educación de Adultos. Revista de la Universidad de Buenos Aires, V Época, Ano VI, n. 4, p. 743-752, 1961.

UNODC. Los trataos internacionales de fiscalización de drogas. Nueva York: [s.n.], 2013.

ZAITCH, Damián. Reducción de daños, seguridad y tráfico de drogas. Revista Cuadernos de Seguridad, n. 1112, p. 51-80, 2009. Disponível em: <http://www.minseg.gob.ar/sites/default/files/cuadernos/11_zaitch.pdf〉. Acesso em: 20 abr. 2018.

Recebido em: 28/07/2018.

Aceito em: 30/12/2018.

\section{POLÊM!CA $\mid$ LABORË}

